\title{
Extrahepatic Bile Duct Carcinoma
}

National Cancer Institute

\section{Source}

National Cancer Institute. Extrahepatic Bile Duct Carcinoma. NCI Thesaurus. Code C3860.

A carcinoma that arises from the extrahepatic bile ducts. The majority are adenocarcinomas. 